\title{
Literature Review on Product Distinctiveness Evaluation and Consumer Choice Based on Need for Uniqueness
}

\author{
Min Gao ${ }^{1,2}$, Bingqun Cui ${ }^{1}$ \\ ${ }^{1}$ School of Economics and Management, Southwest Jiaotong University, Chengdu, China \\ ${ }^{2}$ School of Business Planning, Chongqing Technology and Business University, Chongqing, China \\ Email: linlygao@163.com
}

Received 5 July 2016; accepted 19 July 2016; published 22 July 2016

Copyright (C) 2016 by authors and Scientific Research Publishing Inc.

This work is licensed under the Creative Commons Attribution International License (CC BY). http://creativecommons.org/licenses/by/4.0/

c) (i) Open Access

\begin{abstract}
Product distinctiveness evaluation based on need for uniqueness is a fundamental psychological process in consumer choice, and researchers have found some results about it. From product feature comparison perspective, this article arranges these influence factors and establishes the structural system of consumer evaluation for product distinctiveness, and summarizes the researches achievements in this field.
\end{abstract}

\section{Keywords}

Product Distinctiveness, Need for Uniqueness, Feature Comparison, Choice Set

\section{Introduction}

Influence of need for uniqueness on consuming behaviors is always an important research perspective for scholars, which overturns traditional theory of interpersonal attraction and reveals influences of perceptive similarity on customer choice for unique products. It is shown from theory of interpersonal attraction that level of similarity among people decides their relations, the higher the level of similarity is, the higher the acceptance level will be, that is, birds of a feather flock together [1]. Therefore, individuals will increase level of similarity to blend in the group through herd behavior. However, positive relationship between level of similarity and acceptance level is denied by theory of uniqueness. According to theory of uniqueness, when individuals find their social environments are highly similar to others, they will attempt to reshape their own self-esteem through self-distinguished behaviors in order to reduce negative emotions [2]. Need for uniqueness is stimulated in such condition and affects choice behaviors of consumers [3]. 
It is found from previous researches that consumer objectives can be realized by possessions [4]. And the consuming behavior to purchase unique products and to show the differences from others can meet the need for uniqueness of individuals, thus consumers are willing to purchase unique products to demonstrate their differences with the others and to establish and improve their own images in others' mind so as to meet individual need for uniqueness [3]. Product distinctiveness plays a role in reduction of product fungibility and in resistance of competitors' influences [5]. Thus, for the enterprises, evaluation method and element research by consumers for product distinctiveness have essential reference values and practical meanings. So, driven by need for uniqueness, how do consumers evaluate whether products have distinctiveness and choose it?

Combined with domestic and overseas latest research results, the paper arranges divisional dimensions of evaluation for product distinctiveness and establishes the structural system which influences consumers' evaluation and choice on product distinctiveness from perspective of product attribute comparison, and meanwhile integrates research achievements of the field in this system.

\section{Product Distinctiveness Evaluation Framework}

Product distinctiveness evaluation is the ability of consumers to perceive products different from competitors [6]. Information concern and processing are the primary processes to evaluate product distinctiveness. Due to limitations of cognitive resources, information processing ability of consumers is restricted, thus it is hard for them to make decisions in the complete information situations, but they will choose some information to be processed and deduced. Therefore, it is essential that what kind of information consumers will choose to assist in decision-making. According to the opinion of selective processing, consumers will firstly pay attention to the information in accordance with their own targets, that is, the concern of consumers to specific product information is goal-driven [7]. When consumers are driven by need for uniqueness, they need to purchase products which can represent uniqueness to show their differences [3]. When processing information, consumers shall firstly pay attention to the product information which can realize individual need for uniqueness and the product information to represent uniqueness is the focus of selective processing by consumers. Thus, consumers' evaluation for product distinctiveness is firstly the selective processing process of cognitive resource allocation, and secondly the process to dispose information and evaluate product uniqueness [8].

Difference and uniqueness are derived from comparison. In the process of consumer's choice, their judgments and preference are almost completed by comparison, thus comparison is a basic psychological process for evaluation and choice of consumers [9]. However, in the comparative process, attribute comparison is an important constituent part [10]. Scholars focus on two parts for researches of attribute comparison. One kind is product attribute comparison information based on choice set with the same attribute but different attribute values so that difference and uniqueness can be represented. According to scholars' current researches, choice sets can be divided into two types, namely, binary and multiple choice sets. In addition, unique and divergence attributes in these two kinds of choice sets are respectively represented as distinctiveness information of products. The other is the attribute comparison information unrelated to choice set, which means the product possesses attributes that other candidate products don't have, that is novel attribute and product distinctiveness also can be reflected by novel attribute. The product distinctiveness evaluation framework is as shown in Figure 1.

\section{Need for Uniqueness (NFC)}

Need for uniqueness means the self-imagination and social intention for individuals who acquire, utilize and process consumer goods which can construct and strengthen personal and social identities to develop and improve themselves [11]. The phrase, need for uniqueness, is derived from theory of uniqueness. The theory of uniqueness shows people emphasize the pursuit and balance of level of similarity with others. When level of similarity is increased from low to medium degree, people will create positive emotions such as love and acceptance, thus generate the belonging need. While when level of similarity is grown from medium to extreme degree, people will produce negative emotions and motivate individuals' need for uniqueness, that is, individuals' need for uniqueness is required to be aroused when they perceive the level of similarity is extremely high with others and then they will take difference-seeking action to increase difference degree from others. When individuals judge they have medium level of similarity to almost all the social groups, they won't take any action to change the situation [12].

Driven by need for uniqueness, people choose and purchase distinctive products to decrease adverse impacts 


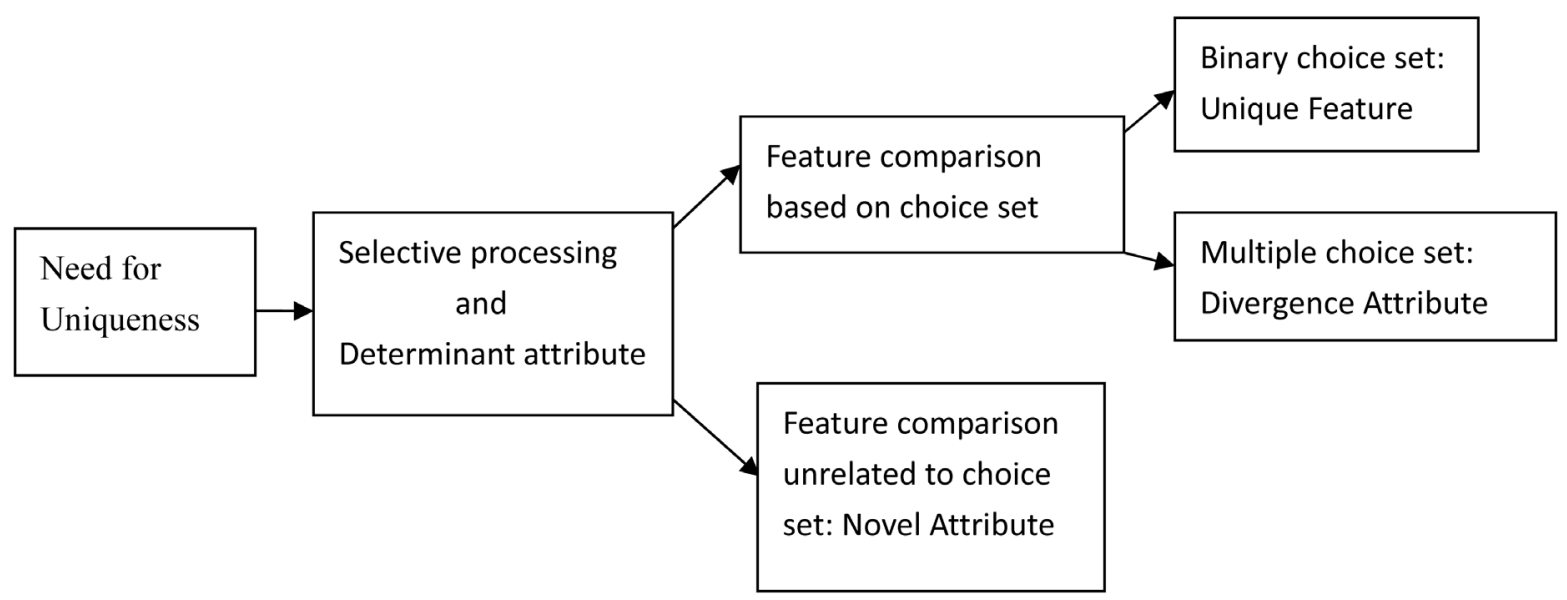

Figure 1. Product distinctiveness evaluation framework based on feature comparison.

brought by individual homogenization [2] [13]. Consumers will positively pursue distinctive products or experience to show their own unique social images different from others [14]-[16]. According to researches of Tian et al. (2001), it is found consumers' need for uniqueness has three behavioral manifestation modes: creative choice counter-conformity, unpopular choice counter-conformity and avoidance of similarity. Creative choice counter-conformity means that these consumers intend to show personality, unique identity and the differences with the others. Consumer behavior usually includes purchasing new or exotic products; Unpopular choice counter-conformity refers that these consumers choose or use the unique product to show a unique performance but their choice deviates from the group norms so that consumers need bearing the condemnation from society; Avoidance of similarity is that these consumers are not interested in popular product and avoid using it, that is aimed at avoiding social identity and building their own differences. All three modes demonstrate consumers possessed with need for uniqueness will actively break the convention and take relevant actions to consciously seek for differences from others [11].

\section{Feature Comparison Based on Choice Set}

Since Tversky (1977) proposed Feature Matching Model to start more and more researches related to feature comparison [10], the feature comparison research has aroused wide interests in academic circles and obtained abundant research results [9] [10] [17]. The conditions of attribute comparison based on choice set include: due to a lack of product knowledge, consumers cannot judge strengths and weaknesses by feature knowledge, but only depend on feature distribution of choice set for helping judgment. Since when feature description is sufficient enough and consumers are familiar enough with features, they can reasonably evaluate and select the product and overlook the influences of choice set structure [18]. However, it is seen from researches related to feature comparison that feature comparison is increasingly developed in the form and changed from comparative research on binary choice set to interactive comparison of multiple choice set. In different choice set structures, attributes to affect product distinctiveness evaluation are various.

\subsection{Feature Comparison in Binary Choice Set: Role of Unique Feature}

In feature comparison of binary choice set, common features and unique features are both concerned in different degrees. Common feature has the same dimensions and value, while unique feature shows different dimensions and value [9] [10]. Scholars find in the situation of forced selection, common features of products will be offset in comparison process, while unique features will attract more attentions, thus common features cannot provide any information and have few effects on evaluation of consumers' choice. Therefore, common feature cannot play the role in feature comparison of binary preference set because of its offset effect. However, different from common feature, unique features provide differential information, generate selective processing for consumers, thus they play a huge role in uniqueness evaluation and preference choice of consumers [9] [10] [19]. Different scholars verify effectiveness of unique features in consumer choice from different perspectives in subsequent 
researches.

Chinese scholar, Li Shu (2005), proposed the Equate-to-differentiate Theory aimed at feature difference comparison in binary choice set and sought for advantageous perspectives to explore consumers' information comparison and choice behavior in consumer information processing [20]. The theory shows, limited by information processing ability, people will firstly regard features with relatively small differences in one or several dimensions as common features in order to overlook them artificially and only pay attention to dimensions with big differences. In addition, people will be attracted by unique features and select advantageous options from them.

It is found from the analysis above that on account of offset effect of common features and selective processing of unique features, consumers prefer to choose unique features for comparison in binary choice set. Unique feature is the key factor to influence consumer choices.

\subsection{Feature Comparison in Multiple Choice Set: Role of Divergence Attribute}

For researches on feature comparison in multiple choice set, scholars propose compromise effect and attraction effect based on feature difference comparison to reveal consumer choice behaviors formed by difference comparison in multiple choice set [21] [22]. Attraction effect is to newly add a relatively bad scheme in original choice set in order to increase chosen probability of advantageous schemes [21]; while compromise effect means all features of target scheme shall be in the centered level by introduction of new schemes so as to affect consumers to choose compromise effect [22]. New scheme is introduced in both effects above to analyze influences of choice set structure on consumer preference and choice without product distinctiveness evaluation. Therefore, the multiple choice set which influences product distinctiveness evaluation is mainly related to research on comparison of feature differences and similarities.

There are few researches on comparison of feature differences and similarities in multiple choice set and the perceptual focusing effect recently found is the main research. Perceptual focusing effect shows perception with similar elements will lead dissimilar elements to be easier concerned, thus attentions of decision makers will be attracted to dissimilar options or feature values [23]. Thus, constituent parts of choice set can affect consumers' perceptual focusing and repetitive common features guide unique features to be focused by perception. In addition, divergence attribute value represented particularly in unique features will be further emphasized [24]. Meanwhile, perceptual focusing effect will also enhance preference of consumers for focused scheme in order to increase its perceptual attraction and choice probability [24] [25].

\section{Feature Comparison Unrelated to Choice Set: Role of Novel Features}

Novel features are new product features usually unknown by general consumers [26]. With development of modern technologies, lots of emerging products add new features, but for most consumers, these new features are part of novel features. Therefore, many novel features always can arouse innovative perception and advanced imagination of consumers [26]. From numerous previous researches, it is verified when new features are added into products, it will have positive effects on consumer evaluation [26]-[29]. For example, if features which consumers are familiar with [27] and high-tech features [28] are included in products, positive evaluations of consumers can be increased and their choices will be affected. In addition, consumers' perceptions may be influenced even novel features are irrelevant [29]. Meanwhile, for products with low complexity, the newly added novel features can promote their positive evaluations by consumers; while for high-complexity products, it is easy to create negative emotions by consumers and make unfavorable evaluations for products when adding novel features [26].

Enterprises always add some features to strengthen product characteristics or increase differences. Houston et al. (1995) implemented researches and found when consumers select products, it is easier for products with unique features to be concerned and the purchasing intentions will be improved [19]. Thus, the participation of novel features can promote consumers' unique perceptions and evaluations as well as has influences on consumer choices. Lots of researches implemented by scholars provide effective reference for enterprises' product design and formulation of marketing strategies.

\section{Conclusion \& Expectation}

Since product distinctiveness evaluation based on need for uniqueness is a complicated process including selec- 
tive processing and activation of external cues, there are different factors to affect product distinctiveness evaluation aimed at various types of feature comparison. The paper analyzes and summarizes the factors of consumers to affect product distinctiveness evaluation driven by need for uniqueness from perspective of consumers' feature comparison, which is beneficial for enterprises to adjust relevant strategies according to their own product features and market environment. By integration of relevant researches on feature comparison, we find the expansion is not enough by scholars related to complicated choice situations with introduction of complex feature combination and new variables. In addition, cross influence mechanism of kinds of influence factors is required to be profoundly explored. Driven by need for uniqueness, influence factors need to be further excavated when consumers are faced with diverse external situations and complicated feature comparison.

\section{References}

[1] Simpson, J.A. and Rholes, W.S. (1998) Attachment Theory and Close Relationships. Guilford Press, New York, 46-76.

[2] Snyder, C.R. and Fromkin, H.L. (1980) Uniqueness: The Human Pursuit of Difference. Plenum Press, New York, 145, 382-391. http://dx.doi.org/10.1007/978-1-4684-3659-4

[3] Tian, K.T. and McKenzie, K. (2001) The Long-Term Predictive Validity of the Consumers' Need for Uniqueness Scale. Journal of Consumer Psychology, 10, 171-193. http://dx.doi.org/10.1207/s15327663jcp1003_5

[4] Brewer, M.B. (1991) The Social Self: On Being the Same and Different at the Same Time. Personality and Social Psychology Bulletin, 17, 475-482. http://dx.doi.org/10.1177/0146167291175001

[5] Caves, R.E. and Williamson, P.J. (1985) What Is Product Differentiation, Really? Journal of Industrial Economics, 34, 113-132. http://dx.doi.org/10.2307/2098677

[6] Rego, L.L., Billett, M.T. and Morgan, N.A. (2009) Consumer-Based Brand Equity and Firm Risk. Journal of Marketing, 73, 47-60. http://dx.doi.org/10.1509/jmkg.73.6.47

[7] Bettman, J.R., Luce, M.F. and Payne, J.W. (1998) Constructive Consumer Choice Processes. Journal of Consumer Research, 25, 187-217. http://dx.doi.org/10.1086/209535

[8] Wang, H., Wang, J. and Luo, J. (2012) The Effect of Ingredient Brand Strategies on Product Distinctiveness Evaluation: The Moderating Role of Self-Construal and Product Nature. Nankai Business Review, 15, 111-117.

[9] Dhar, R. and Sherman, S.J. (1996) The Effect of Common and Unique Features in Consumer Choice. Journal of Consumer Research, 23, 193-203. http://dx.doi.org/10.1086/209477

[10] Tversky, A. (1977) Features of Similarity. Psychological Review, 84, 327-352. http://dx.doi.org/10.1037/0033-295X.84.4.327

[11] Tian, K.T., Bearden, W.O. and Hunter, G.L. (2001) Consumers’ Need for Uniqueness: Scale Development and Validation. Journal of Consumer Research, 28, 50-66. http://dx.doi.org/10.1086/321947

[12] Snyder, C.R. (1992) Product Scarcity by Need for Uniqueness Interaction: A Consumer Catch Carousel? Basic and Applied Social Psychology, 13, 9-24. http://dx.doi.org/10.1207/s15324834basp1301_3

[13] Belk, R.W. (1988) Possessions and the Extended Self. Journal of Consumer Research, 15, 139-168. http://dx.doi.org/10.1086/209154

[14] Lynn, M. and Harris, J. (1997) The Desire for Unique Consumer Products: A New Individual Differences Scale. Psychology and Marketing, 14, 601-616. http://dx.doi.org/10.1002/(SICI)1520-6793(199709)14:6<601::AID-MAR5>3.0.CO;2-B

[15] Richins, M.L. (1994) Special Possessions and the Expression of Material Values. Journal of Consumer Research, 21, 522-533. http://dx.doi.org/10.1086/209415

[16] Fisher, R.J. and Price, L.L. (1992) An Investigation into the Social Context of Early Adoption Behavior. Social Science Electronic Publishing, 19, 477-486. http://dx.doi.org/10.1086/209317

[17] Hedgcock, W. and Rao, A.R. (2009) Trade-Off Aversion as an Explanation for the Attraction Effect: A Functional Magnetic Resonance Imaging Study. Journal of Marketing Research, 46, 1-13. http://dx.doi.org/10.1509/jmkr.46.1.1

[18] Shocker, A.D. and Stewart, D.W. (1987) Toward Understanding the Attraction Effect: The Implications of Product Stimulus Meaningfulness and Familiarity. Journal of Consumer Research, 13, 520-533. http://dx.doi.org/10.1086/209085

[19] Houston, D.A. and Sherman, S.T. (1995) Cancellation and Focus: The Role of Shared and Unique Features in the Choice Process. Journal of Experimental Social Psychology, 31, 357-378. http://dx.doi.org/10.1006/jesp.1995.1016

[20] Li, S. (2005) Choice Reversals across Certainty, Uncertainty and Risk: The Equate to Differentiate Interpretation. Acta Psychologica Sinica, 37, 427-433. 
[21] Huber, J., Payne, J.W. and Puto, C. (1982) Adding Asymmetrically Dominated Alternatives: Violations of Regularity and the Similarity Hypothesis. Journal of Consumer Research, 9, 90-98. http://dx.doi.org/10.1086/208899

[22] Simonson, I. (1989) Choice Based on Reasons: The Case of Attraction and Compromise Effects. Journal of Consumer Research, 16, 158-174. http://dx.doi.org/10.1086/209205

[23] Duncan, J. and Humphreys, G.W. (1989) Visual Search and Stimulus Similarity. Psychological Review, 96, $433-458$. http://dx.doi.org/10.1037/0033-295X.96.3.433

[24] Hamilton, R. and Chernev, A. (2007) Perceptual Focus Effects in Choice. Journal of Consumer Research, 34, 187-199. http://dx.doi.org/10.1086/519147

[25] Chernev, A. (2005) Context Effects without a Context: Attribute Balance as a Reason for Choice. Journal of Consumer Research, 32, 213-223. http://dx.doi.org/10.1086/432231

[26] Mukherjee, A. and Hoyer, W.D. (2001) The Effect of Novel Attributes on Product Evaluation. Journal of Consumer Research, 28, 462-472. http://dx.doi.org/10.1086/323733

[27] Nowlis, S.M. and Simonson, I. (1996) The Effect of New Product Features on Brand Choice. Journal of Marketing Research, 33, 36-46. http://dx.doi.org/10.2307/3152011

[28] Ziamou, P. and Ratneshwar, S. (2002) Promoting Consumer Adoption of High-Technology Products: Is More Information Always Better? Journal of Consumer Psychology, 12, 341-351. http://dx.doi.org/10.1207/15327660260382379

[29] Meyvis, T. and Janiszewski, C. (2002) Consumers’ Beliefs about Product Benefits: The Effect of Obviously Irrelevant Product Information. Journal of Consumer Research, 28, 618-634. http://dx.doi.org/10.1086/338205

\section{Submit or recommend next manuscript to SCIRP and we will provide best service for you:}

Accepting pre-submission inquiries through Email, Facebook, LinkedIn, Twitter, etc.

A wide selection of journals (inclusive of 9 subjects, more than 200 journals)

Providing 24-hour high-quality service

User-friendly online submission system

Fair and swift peer-review system

Efficient typesetting and proofreading procedure

Display of the result of downloads and visits, as well as the number of cited articles

Maximum dissemination of your research work

Submit your manuscript at: http://papersubmission.scirp.org/ 